\title{
COLOR STABILITY OF VITA CLASSICAL SHADE GUIDE AFTER ARTIFICIAL ACCELERATED AGING
}

\author{
Mazen Attia*, Lomaya Ghanem*** and Tamer Hamza***
}

\begin{abstract}
Statement of problem: If there is a noticeable color alteration in the shade guide, the result will be improper shade selection and consequently an unacceptable esthetic restoration. The effect of different weathering conditions on shade guides is still unclear.
\end{abstract}

Purpose: The purpose of this study was to determine the effect of artificial accelerated aging on the color stability of Vita classic shade guide.

Material and methods: The color parameters of the Vita classical shade guide tabs $(n=160)$ were calculated before and after artificial accelerated aging (AAA) in a weathering machine using a spectroradiometer based on the CIE $\mathrm{L}^{*} \mathrm{a}^{*} \mathrm{~b}^{*}$ system. $\mathrm{L}^{*}, \mathrm{a}^{*}$, and $\mathrm{b}^{*}$ coordinates and $\Delta \mathrm{E}^{*}$ were statistically analyzed using one-way analysis of variance followed by Bonferroni test $(\alpha=.05)$.

Results. There was a statistically significant difference for $\mathrm{L}^{*}, \mathrm{a}^{*}$, and $\mathrm{b}^{*}$ coordinates for all specimens, creating darker specimens with a decrease in the $\mathrm{L}^{*}$ coordinate value $(\mathrm{P}<0.001)$, and more reddishlyellowish specimens with an increase in $\mathrm{a}^{*}$ and $\mathrm{b}^{*}$ coordinate values $(\mathrm{P}<0.001)$.

Conclusion: Color changes were observed in all shade tabs after accelerated aging.

Clinical implications: Dentists should be aware of their shade guides after one year clinical service to achieve more esthetic results.

\section{INTRODUCTION}

The increased patients demand to improve their dental esthetics has led to the development of new tooth-colored ceramic restorations; however, accurate color matching of the restoration to the adjacent teeth and the subsequent dentist-laboratory communication remain one of the most critical procedures in clinical dentistry. ${ }^{(1,2)}$

Several factors influence the esthetic success of dental ceramic restorations, ${ }^{(3)}$ such as surface or substrate characteristics, ${ }^{(4,5)}$ marginal accuracy, ${ }^{(6)}$ ceramic thickness, ${ }^{(7)}$ translucency, ${ }^{(8)}$ underlying

* Lecturer, Fixed Prosthodontics Department, Faculty of Dentistry, Beni Suef University, Beni Suef, Egypt.

** Associate Professor, Fixed Prosthodontics Department, Faculty of Dentistry, Misr International University, Cairo, Egypt. *** Professor, Crown and Fixed Prosthodontics Department, Faculty of Dental Medicine, Al-Azhar University, Cairo, Egypt. 
cement, and proper shade selection. ${ }^{(9)}$ According to the literature, accurate color match of a ceramic restoration with the surrounding teeth is still doubtful. ${ }^{(10)}$ Therefore, many factors, such as eye exhaustion, viewing conditions, experience of the operator, light source, back ground and available shade guides play a dominant role in color determination. ${ }^{(1,12)}$

Tooth color can be determined using instrumental methods, such as spectrophotometer, spectroradiometer, colorimeter or visual method using commercially shade guides which are preferred by many clinicians. ${ }^{(13)}$ It has been reported that the precision of shade selection can be reduced to approximately $48 \%$ when a shade guide is used. ${ }^{(14)}$

The Vitapan classical shade guide (Vita Zahnfabrik, Bad Säckingen, Germany) is considered the gold standard and the most commonly used guide for shade selection in esthetic dentistry. ${ }^{(15)}$ Although the guide is made from acrylic resin, it is compatible with porcelain systems. ${ }^{(16)}$ It contains 16 tabs and divided into four groups based on hue formulated by the letters: A (reddish/brownish), B (reddish/yellowish), C (grayish), or D (reddish/ gray). An exact letter group contains shade tabs with the same hue, and each hue group is further grouped by increasing chroma and decreasing value, formulated in numeric order, such as B1, B2, $\mathrm{B} 3$, and B4. ${ }^{(11)}$

The most commonly used method to evaluate the color difference is the CIE L*a*b* color measuring system, developed by the Commission Internationale de l'Eclairage (International Commissionon Illumination) in 1978. ${ }^{(17,18)}$ The system define the color of an object within three-dimensional color space which depends on the human color perception according to three coordinates ( $\mathrm{L}^{*}, \mathrm{a}^{*}$, and $\left.\mathrm{b}^{*}\right)$. $^{(19)}$ The $\mathrm{L}^{*}$ coordinate (y-axis) represents the lightness of an object with a range from 0 (absolute black) to 100 (absolute white) (increased L* value means a lighter shade), the $a^{*}$ coordinate (x-axis) represents the red (positive) or green (negative) chroma, and the $b^{*}$ coordinate(z-axis) represents the yellow (positive) or blue (negative) chroma. ${ }^{(20,21)}$

Color stability of the shade guide over time is a critical factor that may influence shade selection. Most dental clinicians use a shade guide that remains in use throughout the practice service; however, exposure to ultraviolet light can cause changes in color, especially if they are made of resin. ${ }^{(22,23)}$ Artificial accelerated aging can simulate the oral condition; thus, it is employed to determine the color changes in a shade guide after exposure to ultraviolet light and changes in humidity and temperatures. ${ }^{(6)}$

Evidence is lacking with respect to how the exposure of different light sources in the dental clinic affects the color stability of the shade guide. Therefore, the purpose of this study was to determine the effect of artificial accelerated aging on the color stability of Vita classical shade guide. The null hypothesis was that no color change would occur in the shade guide tabs after accelerated artificial aging.

\section{MATERIAL AND METHODS}

One hundred and sixty shade tabs were randomly selected from ten un-used Vitapan classical shade guides and divided into four groups according to hue group in an attempt to cover all essential hues and a broad range of chromas and values. The shade tabs within the same shade group were first inspected visually for any observable color differences.

Color measurements in the current study were done prior to accelerated aging using a non-contact spectroradiometer (PR 705; Photo Research Inc, Chatsworth, Calif) placed $8 \mathrm{~cm}$ away from the measured object with a measurement opening size of $1 \mathrm{~mm}$ and fiber optic light cable attached to a xenon arc lamp (300W; Newport Corp-Oriel Instruments, Stratford, Conn). Both the spectroradiometer and light cable produces light beam at 45 degrees to the specimen and optical arrangement of zero degree 
observation. Spectral reflectance (radiance) of all specimens was $380-780 \mathrm{~nm}$ with a wavelength interval of $2 \mathrm{~nm}$ (SpectraWin 2.0; Photo Research Inc) and next converted to CIE L*a*b* values (D65 illumination and 2-degree observer). Color parameters of each specimen were obtained and defined as $\left(\mathrm{L}^{*}, \mathrm{a}^{*}, \mathrm{~b}^{*}\right)$ coordinate values using the CIE L*a*b* system.

Subsequently, the shade guide tabs were aged for 540 hours (180 cycles) in an accelerated artificial aging chamber (Weather-O-meter; Atlas Ci35A Xenon $^{\circledR}$, Atlas Material Testing Technology LLC, Chicago, IL, USA) with a total radiant energy of $450 \mathrm{~kJ} / \mathrm{m}^{2}$. One surface of each specimen was exposed to a controlled irradiance xenon arc filtered through borate borosilicate glass at $0.55 \mathrm{~W} / \mathrm{m}^{2}$ at $340 \mathrm{~nm}$. The following parameters were included; a black panel temperature of $38^{\circ} \mathrm{C}$ (dark cycle) and $70^{\circ} \mathrm{C}$ (light cycle), a dry bulb temperature of $38^{\circ} \mathrm{C}$ (dark cycle) and $47^{\circ} \mathrm{C}$ (light cycle), and a humidity of $95 \%$ (dark cycle) and $50 \%$ (light cycle). The test cycle duration was set for 40 minutes light only, 20 minutes light plus front water spray, 60 minutes light only, and 60 minutes dark plus back water spray.

The shade guide underwent the same color measurements after accelerated aging process to determine the total color change $(\Delta \mathrm{E})$, which was calculated using the following formula: ${ }^{(23-25)}$

$$
\Delta \mathrm{E}^{*}=\left[\left(\Delta \mathrm{L}^{*}\right)^{2}+\left(\Delta \mathrm{a}^{*}\right)^{2}+\left(\Delta \mathrm{b}^{*}\right)^{2}\right]^{1 / 2}
$$

where $(\Delta \mathrm{L})$ is the variation of $\mathrm{L}^{*}$ (before and after accelerated aging), $(\Delta a)$ is the variation of $a^{*}$, and $(\Delta b)$ is the variation of $b^{*}$.

The normality of distribution of was assessed by the Kolmogorov-Smirnov and Shapiro-Wilk tests. The values of $\left(\mathrm{L}^{*}\right.$ and $\left.\mathrm{b}^{*}\right)$ revealed normal (parametric) distribution, while $\left(\mathrm{a}^{*}\right)$ values revealed non-normal (non-parametric) distribution. Data were presented as median, mean, standard deviation (SD), maximum, minimum, and 95\% confidence interval for the mean values.
For parametric data, repeated measures analysis of variance (ANOVA) was used to evaluate the effect of aging on color parameters ( $\mathrm{L}^{*}$ and $\mathrm{b}^{*}$ ). One-way (ANOVA) test was used to compare between color changes $(\Delta \mathrm{L}, \Delta \mathrm{a}, \Delta \mathrm{b}$ and $\Delta \mathrm{E})$ of the four shades. Bonferroni's post-hoc test was used for pair-wise comparisons when (ANOVA) test was found to be significant. For non-parametric data, Wilcoxon signed-rank test was used to evaluate the effect of aging on color parameter $\left(\mathrm{a}^{*}\right)$.

A significant level of $\mathrm{P}$ value $\leq 0.05$ was used for all comparisons. Statistical analysis was performed using statistical software (v.20.0; SPSS Inc., Armonk, NY, USA) and IBM ${ }^{\circledR}$ computer (IBM Corporation, Armonk, NY, USA).

\section{RESULTS}

Table I presents the means and standard deviations (SD) of color coordinates $\mathrm{L}^{*}, \mathrm{a}^{*}$, and $\mathrm{b} *$ for each color before and after aging. There was a statistically significant difference for $\mathrm{L}^{*}, \mathrm{a}^{*}$, and $\mathrm{b}^{*}$ coordinates for all specimens, resulting in a decrease in the $\mathrm{L}^{*}$ value $(\mathrm{P}<0.001)$ and an increase in $\mathrm{a}^{*}$ and $\mathrm{b}^{*}$ coordinate values $(\mathrm{P}<0.001)$. It was evident that the specimens became darker and more reddish and more yellowish. Table II presents the total color change and standard deviations of $\left(\Delta \mathrm{L}^{*}\right.$, $\Delta \mathrm{a}^{*}, \Delta \mathrm{b}^{*}$, and $\left.\Delta \mathrm{E}\right)$.

\section{DISCUSSION}

The null hypothesis was that no color change would occur in the shade guide tabs after accelerated artificial aging was rejected. Significant differences were found between the color parameters for all shades, in terms of $\mathrm{L}^{*}, \mathrm{a}^{*}$, and $\mathrm{b}^{*}$ coordinates.

The Vita classical shade guide was selected in this study because it is the commonly used guide in the dental field for many years. ${ }^{(26)}$ It is crucial to examine the direction of the linear changes in the color variables before and after (AAA), as the overall changes in color $(\Delta \mathrm{E})$ are directionless. ${ }^{(13)}$ 
TABLE (I) Descriptive statistics and results of comparison between color parameters before and after aging

\begin{tabular}{|c|c|c|c|c|c|c|c|c|c|c|}
\hline \multirow{2}{*}{$\begin{array}{c}\text { Color } \\
\text { parameter }\end{array}$} & \multirow[b]{2}{*}{ Shade } & \multirow[b]{2}{*}{ Aging } & \multirow[b]{2}{*}{ Mean } & \multirow[b]{2}{*}{ SD } & \multirow[b]{2}{*}{ Median } & \multirow[b]{2}{*}{ Minimum } & \multirow[b]{2}{*}{ Maximum } & \multicolumn{2}{|c|}{$95 \% \mathrm{CI}$} & \multirow[b]{2}{*}{$P$-value } \\
\hline & & & & & & & & $\begin{array}{l}\text { Lower } \\
\text { bound }\end{array}$ & $\begin{array}{l}\text { Upper } \\
\text { bound }\end{array}$ & \\
\hline \multirow{8}{*}{$\left(\mathrm{L}^{*}\right)$} & \multirow{2}{*}{ A } & Before & 72.78 & 3.18 & 73.16 & 68.44 & 76.95 & 70.50 & 78.06 & \multirow{2}{*}{$<0.001 *$} \\
\hline & & After & 70.32 & 2.78 & 70.78 & 66.50 & 73.88 & 68.32 & 72.31 & \\
\hline & \multirow{2}{*}{ B } & Before & 74.04 & 2.64 & 74.01 & 71.11 & 77.01 & 71.83 & 76.24 & \multirow{2}{*}{$<0.001 *$} \\
\hline & & After & 71.43 & 2.31 & 71.47 & 68.72 & 74.07 & 69.50 & 73.37 & \\
\hline & \multirow{2}{*}{$\mathrm{C}$} & Before & 68.78 & 3.55 & 68.91 & 64.11 & 73.20 & 65.81 & 71.75 & \multirow{2}{*}{$<0.001 *$} \\
\hline & & After & 66.08 & 3.47 & 66.21 & 61.52 & 70.39 & 63.18 & 68.98 & \\
\hline & \multirow{2}{*}{$\mathrm{D}$} & Before & 72.49 & 1.48 & 72.47 & 70.85 & 74.16 & 70.94 & 74.05 & \multirow{2}{*}{$<0.001 *$} \\
\hline & & After & 70.08 & 1.16 & 70.00 & 68.82 & 71.42 & 68.86 & 71.30 & \\
\hline \multirow{8}{*}{$\left(a^{*}\right)$} & \multirow{2}{*}{ A } & Before & 0.56 & 1.29 & 1.01 & -1.44 & 1.79 & -0.37 & 1.48 & \multirow{2}{*}{$0.005^{*}$} \\
\hline & & After & 1.77 & 1.10 & 2.16 & 0.01 & 2.82 & 0.98 & 2.55 & \\
\hline & \multirow{2}{*}{ B } & Before & -0.58 & 0.96 & -0.72 & -1.55 & 0.65 & -1.38 & 0.22 & \multirow{2}{*}{$0.011^{*}$} \\
\hline & & After & 0.62 & 0.71 & 0.45 & -0.03 & 1.60 & 0.02 & 1.21 & \\
\hline & \multirow{2}{*}{$\mathrm{C}$} & Before & 0.26 & 1.14 & 0.18 & -1.17 & 1.84 & -0.70 & 1.21 & \multirow{2}{*}{$0.011 *$} \\
\hline & & After & 1.50 & 0.98 & 1.50 & 0.21 & 2.78 & 0.68 & 2.31 & \\
\hline & \multirow{2}{*}{$\mathrm{D}$} & Before & -0.04 & 0.56 & -0.24 & -0.53 & 0.66 & -0.62 & 0.55 & \multirow{2}{*}{$0.026^{*}$} \\
\hline & & After & 1.18 & 0.70 & 1.39 & 0.31 & 1.84 & 0.44 & 1.92 & \\
\hline \multirow{8}{*}{$\left(b^{*}\right)$} & \multirow{2}{*}{ A } & Before & 11.77 & 3.02 & 12.91 & 6.95 & 14.91 & 9.61 & 13.93 & \multirow{2}{*}{$<0.001 *$} \\
\hline & & After & 13.52 & 2.82 & 14.73 & 9.01 & 16.39 & 11.51 & 15.54 & \\
\hline & & Before & 10.83 & 4.09 & 11.30 & 5.63 & 15.10 & 7.42 & 14.25 & \\
\hline & & After & 12.56 & 3.92 & 13.07 & 7.58 & 16.53 & 9.29 & 15.84 & \\
\hline & & Before & 10.22 & 1.61 & 10.12 & 8.22 & 12.41 & 8.87 & 11.56 & \\
\hline & & After & 12.16 & 1.47 & 12.06 & 10.36 & 14.16 & 10.93 & 13.38 & \\
\hline & & Before & 10.87 & 2.71 & 10.92 & 7.81 & 13.87 & 8.02 & 13.71 & \\
\hline & & After & 12.50 & 2.49 & 12.58 & 9.68 & 15.25 & 9.89 & 15.12 & \\
\hline
\end{tabular}


TABLE (II) Descriptive statistics and results of comparison between color changes of different shades

\begin{tabular}{|c|c|c|c|c|c|c|c|c|c|}
\hline \multirow{2}{*}{$\begin{array}{l}\text { Color } \\
\text { change }\end{array}$} & \multirow{2}{*}{ Shade } & \multirow{2}{*}{ Mean } & \multirow{2}{*}{ SD } & \multirow{2}{*}{ Median } & \multirow{2}{*}{ Minimum } & \multirow{2}{*}{ Maximum } & \multicolumn{2}{|c|}{$95 \% \mathrm{CI}$} & \multirow{2}{*}{$P$-value } \\
\hline & & & & & & & $\begin{array}{l}\text { Lower } \\
\text { bound }\end{array}$ & $\begin{array}{l}\text { Upper } \\
\text { bound }\end{array}$ & \\
\hline \multirow{4}{*}{$(\Delta \mathrm{L})$} & A & -2.47 & 0.41 & -2.38 & -3.07 & -1.94 & -2.76 & -2.17 & \multirow{4}{*}{0.327} \\
\hline & B & -2.60 & 0.36 & -2.66 & -2.94 & -2.16 & -2.90 & -2.30 & \\
\hline & $\mathrm{C}$ & -2.70 & 0.08 & -2.70 & -2.81 & -2.59 & -2.77 & -2.63 & \\
\hline & $\mathrm{D}$ & -2.41 & 0.32 & -2.47 & -2.74 & -2.03 & -2.75 & -2.08 & \\
\hline \multirow{4}{*}{$(\Delta \mathrm{a})$} & A & 1.21 & 0.21 & 1.15 & 0.98 & 1.45 & 1.06 & 1.36 & \multirow{4}{*}{0.989} \\
\hline & B & 1.20 & 0.28 & 1.13 & 0.95 & 1.59 & 0.96 & 1.43 & \\
\hline & $\mathrm{C}$ & 1.24 & 0.19 & 1.32 & 0.94 & 1.38 & 1.08 & 1.40 & \\
\hline & $\mathrm{D}$ & 1.22 & 0.35 & 1.18 & 0.84 & 1.63 & 0.84 & 1.59 & \\
\hline \multirow{4}{*}{$(\Delta \mathrm{b})$} & A & 1.75 & 0.22 & 1.82 & 1.48 & 2.06 & 1.59 & 1.91 & \multirow{4}{*}{0.052} \\
\hline & B & 1.73 & 0.20 & 1.77 & 1.43 & 1.95 & 1.56 & 1.90 & \\
\hline & $\mathrm{C}$ & 1.94 & 0.15 & 1.94 & 1.75 & 2.14 & 1.82 & 2.06 & \\
\hline & $\mathrm{D}$ & 1.64 & 0.22 & 1.66 & 1.38 & 1.87 & 1.41 & 1.87 & \\
\hline \multirow{4}{*}{$(\Delta \mathrm{E})$} & A & 3.26 & 0.50 & 3.21 & 2.63 & 3.97 & 2.90 & 3.62 & \multirow{4}{*}{0.362} \\
\hline & B & 3.36 & 0.44 & 3.31 & 2.94 & 3.87 & 2.99 & 3.72 & \\
\hline & $\mathrm{C}$ & 3.55 & 0.20 & 3.58 & 3.26 & 3.79 & 3.38 & 3.72 & \\
\hline & $\mathrm{D}$ & 3.16 & 0.50 & 3.20 & 2.59 & 3.70 & 2.64 & 3.69 & \\
\hline
\end{tabular}

\section{*: Significant at $P \leq 0.05$}

To obtain more precise records and for the purpose of standardization, the CIE L*a*b* system was used based on three parameters $\mathrm{L}^{*}, \mathrm{a}^{*}$, and $b^{*}$.Color difference between two objects, which determines whether the changes in the overall shade can be detected by the human eye, can be obtained by comparing the differences between the exacting coordinate values for each object before and after it is subjected to meticulous conditions. ${ }^{(10,21)}$ Ragain et al. ${ }^{(27)}$ revealed that $\Delta \mathrm{E}$ of 2.29 was considered unacceptable as reported by $50 \%$ of the observers. In this study, the mean values of color changes were at unacceptable perception level for all tested groups since $(\Delta \mathrm{E}>2.29)$.
Nevertheless, decrease in mean $\left(\mathrm{L}^{*}\right)$ value after (AAA) indicates loss of brightness. Increase in mean $\left(a^{*}\right)$ indicates that the specimens became more reddish. Increase in mean $\left(b^{*}\right)$ indicates the specimens became more yellow. These results were in accordance with those of Douglas et al. ${ }^{(28)}$ who found that after exposure to 300 hours of accelerated aging, all evaluated materials became darker and more red and yellow.

Artificial accelerated aging is a method claimed to simulate as closely as possible the clinical parameters. The manufacturer claims that 300 hours of weathering in a weather-o-meter equals one year of clinical service intra-orally. ${ }^{(29)}$ Although, there 
are no data to support this claim, ${ }^{(30)}$ this method has been used to assess the clinical performance of many dental materials.

Many studies have used this weathering process to test various dental restorative materials for color stability and surface roughness, including dental composites, resin cements, and dental ceramics as these materials are exposed to several variables intraorally, such as ultraviolet light, changes in temperature, humidity, and mechanical forces. ${ }^{(6,18,30)}$ The use of this method to test the performance and endurance of dental restorative materials in vitro is convenient and can provide us with a more realistic expectation of the long-term outcome of these restorations.

The method of artificial accelerated aging used in the current study is a weathering process marked as CAM 180. This method-as proposed by ASTM G155- is one of several cycles used for exposure of non-metallic materials by xenon-arc light device. It encompasses alternate exposure of darkness and light as well as intermittent exposure to water spray. Validation of the method was verified by previous studies. ${ }^{(6)}$

In this study, the shade tabs were placed in a weathering chamber for 540 hours (equivalent to 18 months) and subjected to different humidity, temperatures, and UV radiation. Hekimoglu et al, ${ }^{(31)}$ found no differences in color changes when (AAA) was applied for long periods in a weathering machine from 300-900 hours. Ertan et al, ${ }^{(30)}$ concluded that color change was induced in the first 100-300 hours when (AAA) was applied.

With this weathering process a question arouse on how many hours in an artificial accelerated aging device equal one year of clinical service? There is no established answer to this question in the literature. However, the device manufacturer claims that 300 hours in the weathering chamber corresponds to one year of clinical service. ${ }^{(24,29)}$
It was suggested that color change caused by artificial accelerated aging involving UV irradiation is related to the internal color stability of the material itself, i.e. intrinsic factors within the material, and occurs mostly within 300 hours of accelerated aging. ${ }^{(18,24,30)}$

The material of shade guide plays an important role in the color stability. Some shade guide tabs are made of porcelain or resin. The industrial fabrication of the shade guide tabs may affect any color change caused by sterilization or weathering conditions. ${ }^{(32)}$ In the current study, all tested shade tabs showed a significant color change after artificial aging; however, the change may either due to change the ceramic tab itself or it can be due to other accessory component which hold the ceramic tab to the metal arms which include some plastic material, so further studies should be conducted to determine the cause of color difference.

It is important to consider that this aging for the shade tab will negatively affect shade color selection and manufactures should work to solve this problem either through indication an expiration date on shade guide or producing new tap which can withstand aging.

Although the VITA classical shade guide is a popular shade guide in the dental clinic, few studies have been done on the effect of (AAA) on the other shade guides that are available on the market such as 3-D Master shade guide, or the Chromascope shade guide; thus, future investigations are required. Also, clinical studies are mandatory to better simulate intraoral conditions to validate the results of this study.

\section{CONCLUSIONS}

Within the limitations of this study, it was found that accelerated artificial aging caused undesirable color changes in the shade guide tabs. 


\section{REFERENCES}

1. Dancy WK, Yaman P, Dennison JB, O’Brein WJ, Razzoog ME. Colour measurements as quality criteria for clinical shade matching of porcelain crowns, J Esthet Restor Dent 2003; 15:114-22.

2. Ishikawa-Nagai S, Yoshida A, Da Silva JD, Miller L. Spectrophotometric analysis of tooth colour reproduction on anterior all-ceramic crowns: Part 1: analysis and interpretation of tooth colour. J Esthet Restor Dent 2010; 22:42-52.

3. Peumans M, Van Meerbeek B, LambrechtsP, Vanherle G. Porcelain veneers: a review of the literature. J Dent 2000; 28:163-77.

4. Shiraishi T, Wood DJ, Shinozaki N, Van Noort R. Optical properties of base dentin ceramics for all-ceramic restorations. Dent Mater 2011; 27:165-72.

5. Wood DJ, Shiraishi T, Shinozaki N, van Noort R. Spectral reflectance and color of dentin ceramics for all-ceramic restorations. Dent Mater 2008; 24:1661-9.

6. Pires-de-Souza Fde C, Casemiro LA, Garcia Lda F, Cruvinel DR. Color stability of dental ceramics submitted to artificial accelerated aging after repeated firings. J Prosthet Dent 2009; 101:13-18.

7. Dozic A, Kleverlaan CJ, Meegdes M, van der Zel J, Feilzer AJ. The influence of porcelain layer thickness on the final shade of ceramic restorations. J Prosthet Dent 2003; 90:563-70.

8. Pecho OE, Ghinea R, Ionescu AM, Cruz Cardona J, Paravina RD, Perez MM. Color and translucency of zirconia ceramics, human dentine and bovine dentine. J Dent 2012; 40:e34-e40.

9. Kürklü D, Azer SS, Yilmaz B, Johnston WM. Porcelain thickness and cement shade effects on the colour and translucency of porcelain veneering materials. J Dent 2013; 41:1043-50.

10. Douglas RD, Steinhauer TJ, Wee AG. Intraoral determination of the tolerance of dentists for perceptibility and acceptability of shade mismatch. J Prosthet Dent 2007; 97:200-208.

11. Watts A, Addy M. Tooth discolouration and staining: a review of the literature. Br Dent J 2001; 190:309-31.

12. Joiner A. Tooth colour: a review of the literature. J Dent 2004; 32:3-12.

13. Alshethri SE. Evaluation of color changes in the Vitapan
Classical Shade Guide after disinfection. Oper Dent 2014; 39:317-24.

14. Okubo SR, Kanawati A, Richards MW, \& Childress S. Evaluation of visual and instrument shade matching. J Prosthet Dent 1998; 80: 642-8.

15. Paravina RD. Evaluation of a newly developed visual shade matching apparatus. Int J Prosthodont 2002; 15: 528-34.

16. Huang PY, Masri R, Romberg E, Driscoll CF. The effect of various disinfectants on dental shade guides. J Prosthet Dent 2014; 112:613-7.

17. Douglas RD, Steinhauer TJ, Wee AG. Intraoral determination of the tolerance of dentists for perceptibility and acceptability of shade mismatch. J Prosthet Dent 2007; 97:200-8.

18. Heydecke G, Zhang F, Razzoog ME. Invitro color stability of double-layer veneers after accelerated aging. J Prosthet Dent 2001; 85:551-7.

19. Uludag B, Usumez A, Sahin V, Eser K, Ercoban E. The effect of ceramic thickness and number of firings on the color of ceramic systems: an in vitro study. J Prosthet Dent 2007; 97:25-31.

20. Yap AU. Color attributes and accuracy of Vita-based manufacturers' shade guides. Oper Dent 1998; 23:266-71.

21. Ghinea R, Pérez MM, Herrera LJ, Rivas MJ, Yebra A, Paravina RD. Color difference thresholds in dental ceramics. J Dent 2010; 38:e57-e64.

22. Leitune VCB, Portella FF, Bohn PV, Collares FM, Samuel SMW. Influence of chlorhexidine application on longitudinal adhesive bond strength in deciduous teeth. Braz Oral Res 2011; 25:388-92.

23. Waldman WR, De Paoli MA. Photodegradation of polypropylene/polystyrene blends: styrene-butadiene-styrene compatibilisation effect. Polym Degrad Stab 2008; 93:273-80.

24. Ruyter IE, Nilner K, Moller B. Color stability of dental composite resin materials for crown and bridge veneers. Dent Mater 1987; 3:246-51.

25. Commission Internationale de l'Eclairage. CIE Technical Report: Colorimetry. CIE Pub No. 15.3. Vienna, Austria: CIE Central Bureau; 2004.

26. Paravina RD, Majkic G, Imai FH, Powers JM. Optimization of tooth colour and shade guide design. Int J Prosthodont 2007; 16:269-76. 
27. Ragain JC, Johnston WM. Color acceptance of direct dental; restoratives by human observers. Color Research and Application 2000; 25:278-85.

28. Douglas RD. Colour stability of new-generation indirect resins for prosthodontic application. J Prosthet Dent 2000; 83:166-70.

29. Turgut S, Bagis B: Color stability of laminate veneers: an in vitro study. J Dent 2011; 39:57-64.
30. Ertan AA, Sahin E. Colour stability of low fusing porcelains: an in vitro study. J Oral Rehabil 2005; 32:358-61.

31. Hekimoğlu C, Anil N, Etikan I. Effect of accelerated aging on the color stability of cemented laminate veneers. Int $\mathrm{J}$ Prosthodont 2000; 13:29-33.

32. Azer SS, Rosenstiel SF, Seghi RR, Johnston WM. Effect of substrate shades on the color of ceramic laminate veneers. J Prosthet Dent 2011; 106:179-83. 